\title{
Des notions concepts en révolution : autour de la liberté politique à la fin du $18 \mathrm{e}$ siècle
}

\section{Marc Belissa}

\section{(2) OpenEdition \\ 1 Journals}

Édition électronique

URL : https://journals.openedition.org/ahrf/1557

DOI : $10.4000 /$ ahrf. 1557

ISSN : 1952-403X

\section{Éditeur :}

Armand Colin, Société des études robespierristes

\section{Édition imprimée}

Date de publication : 1 septembre 2004

Pagination : 211-212

ISSN : 0003-4436

\section{Référence électronique}

Marc Belissa, «Des notions concepts en révolution : autour de la liberté politique à la fin du 18e siècle ", Annales historiques de la Révolution française [En ligne], 337 | juillet-septembre 2004, mis en ligne le 15 février 2006, consulté le 22 avril 2022. URL : http://journals.openedition.org/ahrf/1557 ; DOl : https://doi.org/10.4000/ahrf.1557

\section{Ce document a été généré automatiquement le 22 avril 2022.}

Tous droits réservés 


\title{
Des notions concepts en révolution : autour de la liberté politique à la fin du 18e siècle
}

\author{
Marc Belissa
}

\section{RÉFÉRENCE}

Jacques Guilhaumou et Raymonde Monnier (dir.), Des notions concepts en révolution: autour de la liberté politique à la fin du 18e siècle, vol. 4 des Études révolutionnaires, Paris, Société des études robespierristes, 2003, 196 p., ISBN 2-908327-47-3, 25 e.

1 La quatrième livraison des «Études Révolutionnaires " publiées par notre Société est consacrée aux «notions-concepts en Révolution » et dirigée par Jacques Guilhaumou et Raymonde Monnier. L'ouvrage reprend les neuf communications présentées lors de la journée d'études de la Société du 23 novembre 2002. Cette journée se proposait de rassembler des chercheurs investis à des titres divers dans ce qu'il est convenu d'appeler « l'histoire des concepts» ou «l'histoire du discours» ou encore «l'histoire des notions sociopolitiques ». Comment ces méthodes interprétatives peuvent-elles s'appliquer à l'objet « Révolution française »? Comment l'histoire du langage politique peut-elle aider à une nouvelle compréhension de l'histoire de la Révolution? Telle est la démarche des contributions proposées dans ce volume.

2 Rappelons une fois de plus que cette histoire du discours n'est pas une «histoire des idées », mais celle de la contextualisation (sociale, politique...) du langage. "Histoire des concepts " chez Koselleck ou «Histoire du discours " chez Pocock et Skinner, « analyse du discours » chez Jacques Guilhaumou, autant d'approches qui se combinent dans cet ouvrage. Les «notions » abordées ici sont celles du champ sémantique de la liberté politique : Lumières, constitution, république, liberté de la presse, citoyenneté, espace public, droits des femmes, nation, etc. Les auteurs entendent insister sur les contextes d'élaboration et d'expérimentation des langages politiques. Ils s'intéressent 
particulièrement «à la connexion entre l'approche concrète, par l'archive, des doctrines et des itinéraires de sujets de la langue [...] d'une part, la description de leurs manières de dire à travers des mots, des images, des usages, des traductions, et de façon concomitante leur manière de faire par la médiation d'une imagination créatrice, d'un style, d'une rhétorique, d'une symbolique d'autre part». Cette histoire des notions sociopolitiques ne réduit donc pas l'histoire à une «construction discursive » et n'est pas plus une «réécriture de l'histoire dans les catégories d'analyse du débat contemporain ».

3 La communication de Rolf Reichardt s'intéresse à l'évolution du thème de la victoire des Lumières sur les Ténèbres en utilisant un corpus d'images dans lesquelles la figure de « l'éteignoir » est centrale. Il conclut notamment que le lien entre les Lumières et la Révolution se construit dans l'imaginaire social plutôt après coup, sous la Restauration, que lors des événements révolutionnaires eux-mêmes. L'exposé de Michel Pertué aborde la notion de constitution avant et après la Révolution. Rupture avec l'idée de «lois fondamentales", ce concept ne se construit que progressivement d'où une incapacité à « incarner pleinement une norme impérative qui s'impose aux pouvoirs ». Raymonde Monnier poursuit sa recherche sur la République, cette fois ci dans la théorie de Rousseau en relation avec la «tradition atlantique» de Pocock et Skinner. Elle met à jour notamment les divergences entre Diderot et Rousseau sur le concept de citoyenneté. Christine Fauré s'appuie sur les manuscrits de Sieyès pour interroger le concept d'espace public selon Habermas. L'espace public est pour Sieyès "porteur d'une stratégie de prise de pouvoir». Le législateur-administrateur - plus que le philosophe - est le personnage essentiel de la construction de l'espace public «marqué par le mouvement de légitimation de l'unité nationale ». La contribution d'Agnès Steuckardt étudie les occurrences, les associations et les positions de la notion de liberté de la presse dans l'Ami du Peuple de Marat. Loin d'être un droit défini une bonne fois pour toutes dans la déclaration des droits du 26 août 1789, la liberté de la presse est un concept en construction en relation avec l'expérimentation révolutionnaire. Elle apparaît comme " un droit devenu effectif » et la réflexion sur ses limites (les «abus ») contribue à sa définition. L'étude de Serge Heiden est une présentation de technique lexicométrique à partir d'une modélisation des "cooccurrences» dans un corpus d'orateurs de la Constituante. Une série de lexicogrammes du mot « constitution » chez Mirabeau et Sieyès sert de base à la démonstration. La contribution de Serge Aberdam s'attache à l'articulation entre droits de la femme et notion de citoyenneté chez Mary Wollstonecraft en 1793 et celle de Pierre Serna à celle "d'extrême centre " déjà présentée dans un article de notre revue. Pierre Serna construit la catégorie "d'extrême-centre » pour mieux décrire la position des républicains "modérés » qui, sous le Directoire, refusent le débat d'idée « jugé propre à entretenir le conflit civil » et qui construisent un «apolitisme » républicain partisan d'un exécutif fort. Le corpus étudié ici est celui des articles de la Décade entre 1797 et 1799. Refusant l'idée d'un centre « introuvable» du fait de la radicalisation de droite comme de gauche, Pierre Serna estime au contraire que c'est la radicalisation du centre comme figure du refus « du débat contradictoire » qui explique l'échec d'une stabilisation républicaine et sa dissolution dans le césarisme napoléonien. Enfin, Jacques Guilhaumou traite des rapports entre Willem von Humboldt lors de son séjour parisien et Sieyès. La démarche anthropologique de Humboldt contient une réflexion essentielle sur la langue politique. Quelles relations cette pensée entretient-elle avec la «métaphysique » de Sieyès ? La rencontre des deux hommes dans le cadre du colloque sur la philosophie allemande 
organisé à Paris par les Idéologues est le moment d'une confrontation qui met en jeu différentes conceptions du langage politique.

4 Ce qui est au centre de toutes les interventions de cette journée d'études est donc la richesse et la portée du «travail» de la langue politique révolutionnaire. Les auteurs sont confrontés "à l'effort de la pensée révolutionnaire pour se donner un impact et une cohérence en cherchant sa juste expression à travers des concepts sociopolitiques expérimentés à l'horizon de l'universalité». Si les démarches de "l'histoire des concepts» ou de "l'analyse du discours» ne sont pas toujours explicitement revendiquées par tous les auteurs, leurs contributions sont des exemples des nouvelles approches prometteuses de l'histoire des langages politiques révolutionnaires. 